\title{
Aspirin and non-steroidal anti-inflammatory drug use and the risk of upper aerodigestive tract cancer
}

\author{
T V Macfarlane ${ }^{*}, 1, K$ Lefevre ${ }^{2}$ and M C Watson ${ }^{2}$ \\ ${ }^{1}$ University of Aberdeen Dental School and Hospital, Cornhill Road, Foresterhill, Aberdeen AB25 2ZR, UK and ${ }^{2}$ Centre of \\ Academic Primary Care, University of Aberdeen, Cornhill Road, Foresterhill, Aberdeen AB25 2ZR, UK
}

Background: Aspirin and other non-steroidal anti-inflammatory drugs (NSAIDs) are widely used as analgesics and preventative agents for vascular events. It is unclear whether their long-term use affects cancer risk. Data on the chemopreventative role of these drugs on the risk of the upper aerodigestive tract cancer (UADT) are insufficient and mostly refer to oesophageal cancer. The aim of this study was to investigate the effect of aspirin and other NSAIDs on the risk of UADT cancers.

Methods: A nested case-control study using the Primary Care Clinical Informatics Unit (PCCIU) database. Conditional logistics regression was used for data analysis.

Results: There were 2392 cases of UADT cancer diagnosed between 1996 and 2010 and 7165 age-, gender- and medical practicematched controls from 131 general medical practices. Mean age of cases was 66 years (s.d. 12) and most were male (63\%). Aspirin was prescribed in a quarter of cases and controls, COX-2 inhibitors in $4 \%$ of cases and $5 \%$ of controls and other NSAIDs in $33 \%$ of cases and $36 \%$ of controls. Aspirin prescription was associated with a nonsignificant risk reduction of cancer of UADT (adjusted $\mathrm{OR}=0.9,95 \% \mathrm{Cl}=0.8,1.0$ ), head and neck ( $\mathrm{HN}$; adjusted $\mathrm{OR}=0.9,95 \% \mathrm{Cl}=0.7,1.1)$ or the oesophagus (adjusted $\mathrm{OR}=0.8,95 \%$ $\mathrm{Cl}=0.7,1.0)$. Similar results were found for COX-2 inhibitors prescription. Prescription of other NSAIDs was associated with significantly reduced risk of cancer of UADT (adjusted $\mathrm{OR}=0.8,95 \% \mathrm{Cl}=0.7,0.9$ ), $\mathrm{HN}$ (adjusted $\mathrm{OR}=0.8,95 \% \mathrm{Cl}=0.7,0.9$ ) and the oesophagus (adjusted $\mathrm{OR}=0.8,95 \% \mathrm{Cl}=0.7,0.9$ ). An increased volume of aspirin prescriptions was associated with a significant risk reduction (test for trend $P<0.001$ ).

Conclusions: The decreased risk of cancer of the UADT associated with the use of non-COX-2 inhibitors, NSAIDs and long-term aspirin therapy warrants further exploration of the benefits vs risks of the use of these agents.

Cancer of the upper aerodigestive tract (UADT; oral cavity, pharynx, larynx and oesophagus combined) is, globally, the fourth most common cancer and cause of cancer mortality, with an estimated 1033004 incident cases and 712489 deaths worldwide in 2008 (Ferlay et al, 2010). While a decrease in mortality was noted in the European Union (EU) overall between 1993 and 2004, a persistent rise was observed in central and eastern European countries (Garavello et al, 2010).

Major risk factors for UADT cancer are tobacco consumption, heavy alcohol drinking and poor nutrition, specifically lower fruit and vegetable consumption (IARC Monographs on the Evaluation of Carcinogenic Risks to Humans, 2004, 2010; Lagiou et al, 2009). Other possible risk factors include poor oral hygiene, alcohol in mouthwash and genetic factors (Warnakulasuriya, 2009).

Human papillomavirus (HPV) has been shown to have an aetiological role in head and neck cancers (which include oral cavity, oropharynx, hypopharynx and larynx) irrespective of tobacco and alcohol use (Mork et al, 2001) and may be responsible for the increase in incidence of oropharyngeal squamous cell carcinoma (Mehanna et al, 2010) in the United States between 1999 and 2006, United Kingdom between 1989 and 2006 whereas oropharyngeal cancer had the greatest rate of

*Correspondence: Dr TV Macfarlane; E-mail: Tatiana.Macfarlane@abdn.ac.uk

Received 2 April 2014; revised 24 July 2014; accepted 5 August 2014; published online 11 September 2014

(c) 2014 Cancer Research UK. All rights reserved 0007-0920/14 
increase of any cancer in Scotland in 1987-2006 (Junor et al, 2010).

Recent analysis of individual patient data from randomised clinical trials of daily aspirin (Rothwell et al, 2011) showed a significant reduction in death due to cancer. Few studies have investigated the role of non-steroidal anti-inflammatory drugs (NSAIDs) specifically for UADT cancer (Bosetti et al, 2003; Friis et al, 2006; Macfarlane et $a l, 2012$ ) and the results are not consistent. A recent systematic review of NSAIDs and aspirin use and risk of head and neck cancer did not derive a definitive conclusion, suggesting the need for further studies (Wilson et al, 2011).

The aim of this study was to investigate the effect of aspirin and other NSAIDs use on the risk of UADT cancers. Specific objectives were to investigate risk by cancer sub-site, duration of use and type of NSAIDs.

\section{MATERIALS AND METHODS}

We conducted a nested case-control study using the Primary Care Clinical Informatics Unit (PCCIU) (http://www.abdn.ac.uk/pcciu/) database, which contained information from a sample of general medical practices in Scotland.

The data set consists of complete copies of clinical data for all registered patients. The UK National Health Service (NHS) requires registration with a medical practice to access healthcare services. At the time of data extraction, participating practices systematically used electronic medical records for registration of patients, morbidity recording and prescriptions. The current data includes records up to October 2010 and covers around $15 \%$ of the Scottish population. The data set included age, sex and socioeconomic status, and is representative of all the Scottish patients (Elder et al, 2007).

Ethical permission was not required as the data were anonymised and individuals could not be identified.

Cases and controls. Cases were defined as first time UADT cancer cases (oral cavity, oropharynx, hypopharynx, larynx and oesophagus) diagnosed in 1996 or later. Carcinoma in situ and cases aged $<18$ years at diagnosis were excluded. We used all the available eligible cases in the PCCIU database.

We aimed to identify three controls per case individually matched by age (within 5 years), gender, medical practice and duration of observation in the database, that is, controls should not have follow-up observation time less than cases. In addition, period of exposure considered for controls was truncated so that was not systematically longer than that for the matched controls. Index date for controls was selected from the date of diagnosis of matching cases. Controls aged $<18$ years at index date were excluded.

Both cases and controls with previous history of cancer were excluded (Dregan et al, 2012).

Definition of exposure. We identified prescriptions of oral aspirin, COX-2 inhibitors or other NSAIDs. Any prescriptions before 1990 (because after 1990 the prescriptions were more likely to have been generated electronically and therefore more complete and reliable) and any prescriptions within a year before the diagnosis or index date were disregarded. Topical NSAID preparations were excluded. List of other NSAIDs is shown in Appendix 1.

We defined patients as users if they had at least one prescription. Age at first and last prescription, time between last and first prescription, time between diagnosis and first and last prescriptions and total number of prescriptions were obtained. We also calculated the number of prescriptions per year as the total number of prescriptions divided by time between the last and first prescription.

Confounding factors. Additional data in the database were available on age, gender and practice deprivation (Carstairs index; Carstairs and Morris, 1989). Body mass index (BMI; at least 1 year before the diagnosis/index date) was calculated from height and weight, which were recorded in the database as well as self-reported smoking status and alcohol consumption. Information was obtained on previous history (at least 1 year before diagnosis/ index date) of coronary heart disease (CHD), atrial fibrillation $(\mathrm{AF})$, stroke and lipid-lowering medications. We also investigated the family history of cancer.

Statistical analysis. Conditional logistic regression was used to estimate odds ratios (ORs) with 95\% confidence intervals (CIs). Stratified analysis was conducted using logistic regression adjusted for age, gender and clustering within practices. Crude ORs and adjusted for the potential confounding variables listed above were calculated. Continuous variables were categorised using median or tertiles of the overall distribution. The $\chi^{2}$-test was used for comparison of proportions.

We investigated patterns of missing data and performed both complete data analysis and analysis using multiple imputation (MI). MI ( $n=50$ imputations) was performed using MI procedure in STATA 13 (StataCorp LP, College Station, TX, USA, 2013) for smoking, alcohol consumption and BMI with age, gender and deprivation used in the imputation, separately for cases and controls, using chained logit model. Briefly, MI is a simulationbased approach for analysing incomplete data. MI procedure first replaces missing values with multiple sets of simulated values to complete the data, then applies standard analyses to each completed data set, and finally adjusts the obtained parameter estimates for missing-data uncertainty. The objective of MI is not to predict missing values as close as possible to the true ones but to handle missing data in a way resulting in valid statistical inference (Marchenko, 2011).

Propensity score was used to reduce the impact of selection bias and confounding. Briefly, propensity score is the probability of treatment assignment conditional on observed baseline characteristics (Austin, 2011). The propensity score allows analysis of observational (nonrandomised) studies so that it mimics some of the particular characteristics of a randomised controlled trial. Out of four available methods (matching on the propensity score, stratification on the propensity score, inverse probability of treatment weighting using the propensity score, and covariate adjustment using the propensity score) the inverse probability of aspirin treatment weighting was used. Propensity score (probability that patients had received aspirin prescription) was calculated from logistic regression model with aspirin prescription as outcome and potential confounding factors as predictors. Weight in the model for patients prescribed aspirin was the inverse of the propensity score values whereas the weight for patients not receiving aspirin prescription was the inverse of ( 1 - the propensity score).

Analysis was conducted using IBM SPSS Statistics version 21 (IBM Corp., Released 2012, Armonk, NY, USA) and STATA 13.

\section{RESULTS}

We identified 2392 cases of UADT cancer (1195 of HNC and 1197 oesophageal cancer) and 7165 controls from 131 general medical practices between 1996 and 2010. The majority (2381) of cases had three matched controls and 11 cases had two controls. Mean age of cases was 66 years (s.d. 12) and most were male (67\%).

The proportion of incomplete data for BMI, smoking and alcohol was $43 \%, 24 \%$ and $35 \%$ respectively among cases and $38 \%$, $23 \%$ and $34 \%$ respectively among controls. Complete data were 
available for 1201 (50\%) of cases and 3862 (54\%) of controls. Among cases, complete data were available for $48 \%$ of HNC cases and for 52\% of oesophageal cancer cases. Overall, there was no significant difference in data completeness by gender $\left(\chi^{2} P=0.511\right)$, however, there was variation by age group $(P<0.001)$ with the highest proportion of complete data in 66-75 years age group (57\%) and the lowest in 18-55 age group (47\%). There was a significant difference in data completeness by deprivation $(P<0.001)$ with the highest completeness proportion in the highest deprivation category (59\%). There was a significant difference $(P<0.001)$ in data availability by stroke $(65 \%$ vs $53 \%)$, CHD (67\% vs 51\%), aspirin prescription (71\% vs $47 \%)$, COX-2 inhibitors (76\% vs 52\%) and other NSAIDs (68\% vs $45 \%$; data not shown).

Deprivation was strongly related to risk of UADT cancer (Table $1 ; \mathrm{OR}=2.3,95 \% \mathrm{CI}=1.6,3.2$ ) in most deprived category compared with least deprived; test for trend $P<0.001$. Lower BMI was associated with increased risk of UADT cancer $(\mathrm{OR}=2.6,95 \%$ $\mathrm{CI}=1.5,4.3)$ in patients with $\mathrm{BMI}=15.5-18.4$ compared with $\mathrm{BMI}=30-54$; test for trend $P<0.001$. Individuals categorised as 'ever smokers' had a significantly higher risk of UADT cancer compared with 'never smokers' (Table 1 ; OR $=2.4,95 \% \mathrm{CI}=2.1$, 2.7). Individuals with a high level of alcohol consumption $(\mathrm{OR}=1.7 ; 95 \% \mathrm{CI}=1.4,2.1)$ were at greater risk of UADT cancer than low or non-alcohol consumers. History of CHD and stroke was associated with increased UADT cancer risk: $\mathrm{OR}=1.2,95 \%$ $\mathrm{CI}=1.0,1.4$ and $\mathrm{OR}=1.4,95 \% \mathrm{CI}=1.1,1.8$, respectively. No association was found for history of $\mathrm{AF}(\mathrm{OR}=1.0,95 \% \mathrm{CI}=0.8$, $1.3)$, family history of cancer $(\mathrm{OR}=1.1 ; 95 \% \mathrm{CI}=0.8,1.5)$ or lipidlowering drug prescription $(\mathrm{OR}=1.0 ; 95 \% \mathrm{CI}=0.9,1.2$; Table 1$)$.

Aspirin was prescribed in a quarter of cases and controls, COX-2 inhibitors were prescribed in $4 \%$ of cases and $5 \%$ of controls and other NSAIDs were prescribed in 33\% of cases and $36 \%$ of controls (Table 2). Aspirin prescription was associated with nonsignificant reduction in risk of cancer of UADT (adjusted $\mathrm{OR}=0.9, \quad 95 \% \mathrm{CI}=0.8,1.0$ ), $\mathrm{HN}$ (adjusted $\mathrm{OR}=0.9,95 \%$ $\mathrm{CI}=0.8,1.2$ ) and oesophagus (adjusted $\mathrm{OR}=0.9,95 \% \mathrm{CI}=0.7$, 1.1; Table 2). Similar results were found for COX-2 inhibitors prescriptions. Prescription of other NSAIDs was associated with reduced risk of cancer of UADT (adjusted $\mathrm{OR}=0.8,95 \% \mathrm{CI}=0.7$, 0.9 ), $\mathrm{HN}$ (adjusted $\mathrm{OR}=0.8,95 \% \mathrm{CI}=0.7,0.9$ ) and the oesophagus (adjusted $\mathrm{OR}=0.8 ; 95 \% \mathrm{CI}=0.7,0.9$; Table 2). There was no significant difference in the above OR estimates between cancer of the head and neck and oesophagus $(P>0.05$; Table 2$)$, therefore, these two sites were combined.

Aspirin prescription was significantly associated with older age, deprivation, BMI, smoking, alcohol consumption, history of $\mathrm{CHD}$, $\mathrm{AF}$, stroke and lipid-lowering drug prescription $(P<0.001$; data not shown in tables).

Further analysis of aspirin prescription (ever) showed no change in OR estimates when weighting by propensity score was used in the model (for UADT cancer $\mathrm{OR}=0.9 ; 95 \% \mathrm{CI}=0.7,1.0$ ). Using multiple imputation and additional adjustment for BMI, smoking and alcohol consumption resulted in similar estimate $(\mathrm{OR}=0.9$; $95 \% \mathrm{CI}=0.8,1.0$; data not shown in tables).

When considering patients with complete data only, aspirin prescriptions were not associated with decreased risk of UADT cancer $(\mathrm{OR}=1.0,95 \% \mathrm{CI}=0.9,1.2)$.

There was a significant reduction associated with aspirin prescriptions for females $(\mathrm{OR}=0.7,95 \% \mathrm{CI}=0.6,0.9)$ but not for males $(\mathrm{OR}=1.0,95 \% \mathrm{CI}=0.9,1.2$; test for heterogeneity $P=0.019$; Table 3). There were no differences in OR estimates for aspirin by age, deprivation, BMI, smoking or alcohol (test for heterogeneity $P>0.05$; Table 3 ), however, significant risk reduction associated with aspirin prescriptions was observed among patients with missing data for BMI, smoking and alcohol (Table 3). There was no difference in estimates between males and females when multiple imputation and propensity score were used $(P>0.05$, data not shown in tables).

There was no significant reduction associated with UADT cancer risk for age at first and last aspirin prescription, time between last and first prescription, time between diagnosis and first and last prescription and number of prescriptions per year (Table 4). However there was a significant decrease in risk of UADT cancer with increased number of prescriptions $(\mathrm{OR}=0.8$, $95 \% \mathrm{CI}=0.6,0.9)$ in those with total number of prescription between 29 and 147 compared with never prescription, test for trend $P=0.017$ (Table 4). This result was not significant when analysed separately for cancer of the head and neck and oesophageal cancer $(\mathrm{OR}=0.77,95 \% \quad \mathrm{CI}=0.5, \quad 1.1 \quad$ and $\mathrm{OR}=0.81,95 \% \mathrm{CI}=0.6,1.1$, respectively; data not shown in tables).

\section{DISCUSSION}

This first large Scotland-based general practice-derived case-control study showed a decrease in risk of UADT cancer with a high volume of aspirin prescriptions, that is, $>29$, as well as with the prescription of other NSAIDs (not COX-2 inhibitors). The majority of the UK population is registered with a general medical practice; therefore these results are likely to be representative of the general population.

While our study overall did not show a significant association between ever aspirin prescription and risk of UADT cancer, when considered by total number of prescriptions, aspirin was associated with a reduced risk of UADT cancer for high total number of prescriptions and ever use of other NSAIDs. This finding supports results of a review of aspirin and cancer risk (Wilson et al, 2011), which showed that aspirin use was associated with a reduced risk of cancer of the oesophagus and multicentre study of UADT cancer, which showed that regular aspirin use (at least once a week for a year) was not associated with risk of UADT cancer overall but was associated with a reduced risk for cancer of oesophagus $(\mathrm{OR}=0.5,95 \% \mathrm{CI}=0.3-0.9)$, hypopharynx $\quad(\mathrm{OR}=0.5,95 \%$ $\mathrm{CI}=0.3-1.0) \quad$ and larynx $\quad(\mathrm{OR}=0.7, \quad 95 \% \quad \mathrm{CI}=0.5-1.0$; Macfarlane et al, 2012).

Analysis of individual patient data from eight randomised trials of daily aspirin vs no aspirin (Rothwell et al, 2011) showed a significant reduction in death due to cancer $(\mathrm{OR}=0.8,95 \%$ $\mathrm{CI}=0.7,0.9)$. There were no data reported specifically on head and neck cancer, but there was a nonsignificant decrease in risk of death due to oesophageal cancer (hazard ratio (HR) $=0.8(95 \%$ $\mathrm{CI}=0.3,2.2)$ for $0-5$ years of follow-up and $\mathrm{HR}=0.43(95 \%$ $\mathrm{CI}=0.1,1.7)$ for 5 years follow-up or longer). The overall protective effect of aspirin was more evident for adenocarcinomas $(\mathrm{HR}=0.5,95 \% \mathrm{CI}=0.4,0.8$ for 5 years of follow-up or longer). The protective effect of aspirin in this combined analysis did not appear to increase at doses $>75 \mathrm{mg}$ daily.

Biologically, aspirin and other NSAIDs suppress the production of prostaglandins and thromboxanes by irreversible inactivation of the cyclooxygenase (COX) enzyme which is involved in the mechanism of carcinogenesis (Thun et al, 2002). Other mechanisms include the induction of apoptosis through COX-independent pathways, the inhibition of NFjb factor and the upregulation of tumour suppression genes (Hernández-Díaz and García Rodríguez, 2007).

We have evaluated aspirin and other NSAIDs separately and found stronger chemopreventive effect of other NSAIDs for both $\mathrm{HNC}$ and oesophageal cancer. It was suggested that different types of NSAIDs might have different effects due to residual confounding and biological mechaisms (Hernández-Díaz and García Rodríguez, 2007; Vinogradova et al, 2011). 


\begin{tabular}{|c|c|c|c|}
\hline Characteristics & $\begin{array}{c}\text { Cases } \\
n=2392 \\
N(\%)\end{array}$ & $\begin{array}{c}\text { Controls } \\
n=7176 \\
N(\%)\end{array}$ & $\begin{array}{c}\text { OR }(95 \% \mathrm{Cl})^{\mathrm{a}} \\
\text { Test for trend } P \text {-value }\end{array}$ \\
\hline \multicolumn{4}{|l|}{ Carstairs deprivation category } \\
\hline $\begin{array}{l}1 \text { (Least deprived) } \\
2 \\
3 \\
4 \\
5 \\
6 \\
7 \text { (Most deprived) }\end{array}$ & $\begin{array}{c}94(3.9) \\
199(8.3) \\
404(16.9) \\
785(32.8) \\
380(15.9) \\
259(10.8) \\
271(11.3)\end{array}$ & $\begin{array}{c}365(5.1) \\
665(9.3) \\
1356(18.9) \\
2294(32.0) \\
1043(14.6) \\
738(10.3) \\
704(9.8)\end{array}$ & $\begin{array}{c}1.00 \\
1.19(0.85,1.67) \\
1.20(0.89,1.61) \\
1.56(1.18,2.06) \\
1.73(1.28,2.34) \\
1.80(1.30,2.51) \\
2.26(1.59,3.22) \\
P<0.001\end{array}$ \\
\hline \multicolumn{4}{|l|}{ Body mass index } \\
\hline $\begin{array}{l}30.0-54.0 \\
25.0-29.9 \\
18.5-24.9 \\
15.5-18.4 \\
\text { Missing }\end{array}$ & $\begin{array}{c}260(19.1) \\
520(38.1) \\
552(40.4) \\
33(2.4) \\
1027\end{array}$ & $\begin{array}{c}1051(23.7) \\
1832(41.4) \\
1498(33.8) \\
49(1.1) \\
2735\end{array}$ & $\begin{array}{c}1.00 \\
1.13(0.94,1.35) \\
1.42(1.18,1.71) \\
2.55(1.52,4.28) \\
P<0.001\end{array}$ \\
\hline \multicolumn{4}{|l|}{ Smoking } \\
\hline $\begin{array}{l}\text { Never } \\
\text { Ever } \\
\text { Missing }\end{array}$ & $\begin{array}{l}453(24.9) \\
1370(75.1) \\
569\end{array}$ & $\begin{array}{c}2411(43.7) \\
3109(56.3) \\
1645\end{array}$ & $\begin{array}{c}1.00 \\
2.40(2.10,2.73)\end{array}$ \\
\hline \multicolumn{4}{|l|}{ Alcohol consumption } \\
\hline $\begin{array}{l}\text { No } \\
\text { Low (within recommended limits) } \\
\text { High (above recommended limits) } \\
\text { Missing }\end{array}$ & $\begin{array}{l}329(21.1) \\
884(56.8) \\
344(22.1) \\
835\end{array}$ & $\begin{array}{r}1033(21.8) \\
3057(64.6) \\
645(13.6) \\
2430\end{array}$ & $\begin{array}{c}1.00 \\
0.89(0.75,1.04) \\
1.70(1.37,2.11)\end{array}$ \\
\hline \multicolumn{4}{|c|}{ Coronary heart disease (at least 12 months before diagnosis/index date) } \\
\hline $\begin{array}{l}\text { No } \\
\text { Yes }\end{array}$ & $\begin{array}{r}2007(83.9) \\
385(16.1)\end{array}$ & $\begin{array}{l}6156(85.9) \\
1009(14.1)\end{array}$ & $\begin{array}{c}1.00 \\
1.18(1.04,1.35)\end{array}$ \\
\hline \multicolumn{4}{|c|}{ Atrial fibrillation (at least 12 months before diagnosis/index date) } \\
\hline $\begin{array}{l}\text { No } \\
\text { Yes }\end{array}$ & $\begin{array}{c}2305(96.4) \\
87(3.6)\end{array}$ & $\begin{array}{c}6911(96.4) \\
254(3.6)\end{array}$ & $\begin{array}{c}1.00 \\
1.02(0.80,1.32)\end{array}$ \\
\hline \multicolumn{4}{|c|}{ Stroke (at least 12 months before diagnosis/index date) } \\
\hline $\begin{array}{l}\text { No } \\
\text { Yes }\end{array}$ & $\begin{array}{l}2293(95.9) \\
99(4.1)\end{array}$ & $\begin{array}{c}6946(96.9) \\
219(3.1)\end{array}$ & $\begin{array}{c}1.00 \\
1.38(1.08,1.76)\end{array}$ \\
\hline \multicolumn{4}{|l|}{ Family history of cancer } \\
\hline $\begin{array}{l}\text { No } \\
\text { Yes }\end{array}$ & $\begin{array}{l}2341(97.9) \\
51(2.1)\end{array}$ & $\begin{array}{c}7020(98.0) \\
145(2.0)\end{array}$ & $\begin{array}{c}1.00 \\
1.06(0.76,1.48)\end{array}$ \\
\hline \multicolumn{4}{|c|}{ Lipid-lowering drug prescription (at least 12 months before diagnosis/index date) } \\
\hline $\begin{array}{l}\text { Never } \\
\text { Ever }\end{array}$ & $\begin{array}{r}1943(81.2) \\
449(18.8)\end{array}$ & $\begin{array}{l}5832(81.4) \\
1333(18.7)\end{array}$ & $\begin{array}{c}1.00 \\
1.01(0.89,1.15)\end{array}$ \\
\hline
\end{tabular}

With respect to methodological quality, the study included cancers over several sites in the UADT. No information was available regarding the histological subtype or cancer stage. While these are a heterogeneous group of neoplasms, they have similar aetiologies: regular alcohol consumption and tobacco smoking (Lagiou et al, 2009; IARC Monographs on the Evaluation of Carcinogenic Risks to Humans, 2010). To investigate potential aetiological differences, we conducted additional analyses separately for head and neck cancer and cancer of the oesophagus and did not find significant differences in risk estimates.

Matching controls on sex, age, medical practice and index date removed effects from these confounding factors.

NSAID exposure was measured in terms of prescriptions issued. In the current study we did not have information on dose or indication for use of aspirin or other NSAIDs. The issue of a prescription does not mean that the medicine was actually used. 


\begin{tabular}{|c|c|c|c|c|c|c|c|c|c|c|}
\hline \multirow[b]{2}{*}{ Prescription } & \multicolumn{3}{|c|}{ All UADT cancers } & \multicolumn{3}{|c|}{ Head and Neck cancer } & \multicolumn{3}{|c|}{ Oesophageal cancer } & \multirow[b]{2}{*}{$P$-value ${ }^{\mathrm{b}}$} \\
\hline & $\begin{array}{c}\text { Cases } \\
n=2392 \\
N(\%)\end{array}$ & $\begin{array}{c}\text { Controls } \\
n=7165 \\
N(\%)\end{array}$ & $\begin{array}{c}\text { OR } \\
(95 \% \mathrm{Cl})^{\mathrm{a}}\end{array}$ & $\begin{array}{c}\text { Cases } \\
n=1195 \\
N(\%)\end{array}$ & $\begin{array}{c}\text { Controls } \\
n=3580 \\
N(\%)\end{array}$ & $\begin{array}{c}\text { OR } \\
(95 \% \mathrm{Cl})^{\mathrm{a}}\end{array}$ & $\begin{array}{c}\text { Cases } \\
n=1197 \\
N(\%)\end{array}$ & $\begin{array}{c}\text { Controls } \\
n=3585 \\
N(\%)\end{array}$ & $\begin{array}{c}\text { OR } \\
(95 \% \mathrm{Cl})^{\mathrm{a}}\end{array}$ & \\
\hline \multicolumn{11}{|l|}{ Aspirin } \\
\hline Never & $1798(75.2)$ & $5397(75.3)$ & 1.00 & $936(78.3)$ & $2862(79.9)$ & 1.00 & $862(72.0)$ & $2535(70.7)$ & 1.00 & \\
\hline Ever & $594(24.8)$ & $1768(24.7)$ & $0.90(0.78,1.04)$ & $259(21.7)$ & $718(20.1)$ & $0.93(0.76,1.15)$ & $335(28.0)$ & $1050(29.3)$ & $0.87(0.72,1.05)$ & 0.122 \\
\hline \multicolumn{11}{|l|}{ COX-2 } \\
\hline Never & $2289(95.7)$ & $6783(94.7)$ & 1.00 & $1150(96.2)$ & $3403(95.1)$ & 1.00 & $1139(95.2)$ & 3380 (94.3) & 1.00 & \\
\hline Ever & $103(4.3)$ & $382(5.3)$ & $0.84(0.67,1.06)$ & $45(3.8)$ & $177(4.9)$ & $0.80(0.56,1.13)$ & $58(4.9)$ & $205(5.7)$ & $0.88(0.64,1.21)$ & 0.620 \\
\hline \multicolumn{11}{|c|}{ Other NSAID } \\
\hline Never & $1612(67.4)$ & $4563(63.7)$ & 1.00 & 817 (68.4) & $2314(64.6)$ & 1.00 & $795(66.4)$ & $2249(62.7)$ & 1.00 & \\
\hline Ever & $780(32.6)$ & $2602(36.3)$ & $0.83(0.75,0.93)$ & $378(31.6)$ & $1266(35.4)$ & $0.82(0.70,0.96)$ & $402(33.6)$ & $1336(37.3)$ & $0.84(0.73,0.98)$ & 0.825 \\
\hline \multicolumn{11}{|c|}{ 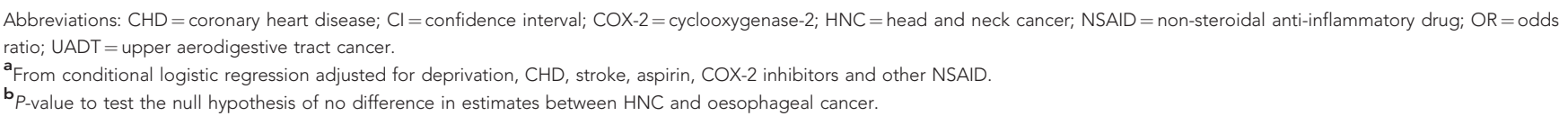 } \\
\hline
\end{tabular}

Questionnaire-based study conducted in UK general medical practices which compared prescribed NSAIDs and described by patients reported mean (s.d.) compliance (percentage of intended dose taken) of 0.73 (0.55) for ibuprofen, $0.76(0.56)$ for diclofenac and 0.76 (0.55) for Naproxen (Hawkey et al, 2000). It is unlikely, however, that non-adherence would differ systematically between cases and controls in our study.

The results will not have been influenced by recall bias because prescriptions were recorded prospectively before the index date. No data were available regarding the use of over-the-counter medications, which contain aspirin and NSAIDs, and this will have underestimated exposure to these medicines. COX-2 inhibitors can only be obtained by prescription in the UK. However the reported prevalence of aspirin prescription is comparable to prevalence of self-reported aspirin use in other studies conducted in the UK (Macfarlane et al, 2012; 22\% in cases and 26\% in controls).

Hernández-Díaz and García Rodríguez (2007) in the study of NSAIDs and risk of lung cancer performed a sensitivity analysis to quantify the impact of misclassification due to unrecorded overthe-counter use or to noncompliance. They concluded that the protective effect could not be explained by the unrecorded use. Yood et al (2007) concluded from their sensitivity analysis that prescription data can give valid estimates of association even though some of the drugs are available over the counter.

Prescriptions for cases before diagnosis could relate to early cancer symptoms before the recorded diagnosis. However we excluded any prescriptions within 1 year of diagnoses.

We defined ever users as those with at least one prescription. Another study of prescriptions (Vinogradova et al, 2011) similarly defined users as those with at least one prescription, whereas Friis et al (2006) defined users as those with two or more prescriptions. Studies which collected information using questionnaires defined users as those who ever took aspirin before the onset of illness (Jayaprakash et al, 2006) or as regular users (use at least once a week for a year; Macfarlane et al, 2012). In our study, among ever users cases and controls, there were $11 \%$ and $12 \%$ with only one prescription, respectively. Defining users as those with at least two prescriptions resulted in adjusted OR of $0.87(0.78,1.55)$ which is similar to our estimates when users were defined as those with at least one prescription.
We adjusted for potential confounders such as deprivation, BMI, smoking, alcohol consumption, medical history and family history of cancer. However the quality of some of this information was poor. For example, there was a large amount of missing data and inconsistency in recording of smoking and alcohol consumption. In addition, we did not have information on other risk factors for UADT, such as poor nutrition (especially low fruit and vegetable consumption), history of HPV infection, poor oral hygiene and genetic factors. However, analyses of US healthcare utilisation data sets indicate that these potential confounders have limited influence in studies of NSAID use and various health outcomes (Schneeweiss et al, 2005). Analysis of the relationship between confounding factors and UADT cancer in our study showed similar association. For example, increased risk was associated with increased deprivation (Conway et al, 2010), low BMI (Gaudet et al, 2010), smoking (IARC Monographs on the Evaluation of Carcinogenic Risks to Humans, 2004) and alcohol consumption (IARC Monographs on the Evaluation of Carcinogenic Risks to Humans, 2010). We also used multiple imputation to replace the missing values for confounding factors.

Systematic review of observation studies of NSAIDs use and upper gastrointestinal tract bleeding and perforation (HernándezDíaz and Rodríguez, 2000) showed an increased pooled relative risk of $3.8(95 \% \mathrm{CI}=3.6,4.1)$. However Rothwell et al (2012) in the study of individual patient data from 51 randomised trials of shortterm effects of daily aspirin on cancer incidence, mortality and non-vascular death showed that the reduced risk of major vascular events was initially offset by an increased risk of major bleeding, but effects on both outcomes diminished with increasing followup, leaving only the reduced risk of cancer from 3 years onwards. Case-fatality from major extracranial bleeds was also lower on aspirin than on control $(\mathrm{OR}=0 \cdot 32,95 \% \mathrm{CI}=0 \cdot 12-0 \cdot 83)$.

The incidence of oral cancer is increasing in many countries (Jemal et al, 2010; Chaturvedi et al, 2013) and the lack of efficient therapy and the considerable associated morbidity and mortality make chemoprevention a realistic possibility (Jemal, 2012), particularly since this might be targeted to high-risk individuals with leukoplakia or other precursor lesions (Nelson, 2006). NSAIDs have shown promise as chemopreventive agents for oral cancer in experimental studies (Goodin and Shiff, 2004). Further 


\begin{tabular}{|c|c|}
\hline Characteristics & $\begin{array}{c}\text { OR }(95 \% \mathrm{Cl}) \\
\text { Test for heterogeneity } \\
P \text {-value }\end{array}$ \\
\hline \multicolumn{2}{|l|}{ Gender } \\
\hline $\begin{array}{l}M \\
F\end{array}$ & $\begin{array}{c}1.02(0.86,1.22)^{a} \\
0.72(0.56,0.91) \\
P=0.019\end{array}$ \\
\hline \multicolumn{2}{|l|}{ Age (years) } \\
\hline $\begin{array}{l}18-55 \\
56-65 \\
66-75 \\
76+\end{array}$ & $\begin{array}{c}0.78(0.46,1.32)^{\mathbf{b}} \\
0.91(0.68,1.21) \\
0.96(0.77,1.19) \\
0.81(0.64,1.02) \\
P=0.269\end{array}$ \\
\hline \multicolumn{2}{|l|}{ Carstairs deprivation category } \\
\hline $\begin{array}{l}1 \text { (Least deprived) } \\
2 \\
3 \\
4 \\
5 \\
6 \\
7 \text { (Most deprived) }\end{array}$ & $\begin{array}{c}0.90(0.45,1.77) \\
0.86(0.53,1.41)^{b} \\
0.94(0.69,1.40) \\
0.87(0.68,1.10) \\
0.77(0.55,1.08) \\
1.14(0.78,1.69) \\
0.85(0.57,1.27) \\
P=0.438\end{array}$ \\
\hline \multicolumn{2}{|l|}{ Body mass index } \\
\hline $\begin{array}{l}30.0-54.0 \\
25.0-29.9 \\
18.5-24.9 \\
15.5-18.4 \\
\text { Missing }\end{array}$ & $\begin{array}{c}1.08(0.77,1.50)^{b} \\
1.32(1.02,1.71) \\
0.88(0.66,1.17) \\
0.75(0.13,4.26) \\
P=0.164 \\
0.65(0.51,0.84)\end{array}$ \\
\hline \multicolumn{2}{|l|}{ Smoking } \\
\hline $\begin{array}{l}\text { Never } \\
\text { Ever } \\
\text { Missing }\end{array}$ & $\begin{array}{c}1.00(0.76 .1 .32)^{b} \\
0.88(0.74,1.05) \\
P=0.108 \\
0.54(0.37,0.79)\end{array}$ \\
\hline \multicolumn{2}{|l|}{ Alcohol consumption } \\
\hline $\begin{array}{l}\text { No or low(within recommended limits) } \\
\text { High (above recommended limits) } \\
\text { Missing }\end{array}$ & $\begin{array}{c}0.97(0.82,1.15)^{b} \\
0.92(0.62,1.37) \\
P=0.978 \\
0.74(0.56,0.97)\end{array}$ \\
\hline \multicolumn{2}{|c|}{ 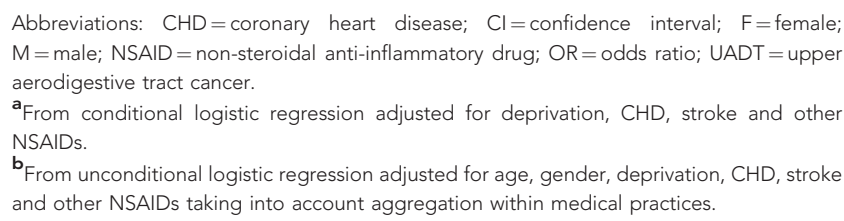 } \\
\hline
\end{tabular}

exploration of the benefits $v s$ risks of the use of these agents is needed.

\section{CONCLUSION}

There is evidence of decreased risk of UADT cancer associated with the use of NSAIDs (non-COX-2 inhibitors) and number of aspirin prescriptions. These findings are important and should be a
Table 4. Aspirin prescription and UADT cancer risk

\begin{tabular}{|c|c|c|c|c|}
\hline Characteristics $^{a}$ & $\begin{array}{c}\text { Cases } \\
n=2392 \\
N(\%)\end{array}$ & $\begin{array}{c}\text { Controls } \\
n=7165 \\
N(\%)\end{array}$ & $\begin{array}{c}\text { OR } \\
(95 \% \mathrm{Cl})^{\mathrm{b}}\end{array}$ & $\begin{array}{l}\text { Test for } \\
\text { trend } \\
\text { (P-value) }\end{array}$ \\
\hline
\end{tabular}

\section{Age at first prescription (years)}

\begin{tabular}{|l|c|c|c|c|}
\hline Never & $1798(75.2)$ & $5397(75.3)$ & 1.00 & 0.112 \\
$26-61$ & $181(7.6)$ & $539(7.5)$ & $0.84(0.68,1.04)$ & \\
$62-70$ & $216(9.0)$ & $625(8.7)$ & $0.90(0.74,1.09)$ & \\
$71-93$ & $197(8.2)$ & $604(8.5)$ & $0.87(0.70,1.08)$ & \\
\hline
\end{tabular}

\section{Age at last prescription (years)}

\begin{tabular}{|l|c|c|c|c|}
\hline Never & $1798(75.2)$ & $5397(75.3)$ & 1.00 & 0.185 \\
$27-66$ & $176(7.4)$ & $577(8.0)$ & $0.76(0.62,0.93)$ & \\
$67-74$ & $210(8.8)$ & $557(7.8)$ & $1.05(0.85,1.28)$ & \\
$75-98$ & $208(8.7)$ & $634(8.9)$ & $0.84(0.67,1.05)$ & \\
\hline
\end{tabular}

Time between last and first prescription (years)

\begin{tabular}{|l|c|c|c|c|}
\hline Never & $1798(75.2)$ & $5397(75.3)$ & 1.00 & 0.102 \\
$<1.5$ & $187(7.8)$ & $586(8.2)$ & $0.86(0.71,1.04)$ & \\
$1.6-5.3$ & $203(8.5)$ & $591(8.3)$ & $0.89(0.73,1.09)$ & \\
$5.4-19.2$ & $204(8.5)$ & $591(8.3)$ & $0.86(0.69,1.06)$ & \\
\hline
\end{tabular}

Time between diagnosis and first prescription (years)

\begin{tabular}{|l|c|c|c|c|}
\hline Never & $1798(75.2)$ & $5397(75.3)$ & 1.00 & 0.061 \\
$1-3$ & $199(8.3)$ & $574(8.0)$ & $0.91(0.75,1.09)$ & \\
$4-6$ & $159(6.6)$ & $497(7.0)$ & $0.84(0.68,1.04)$ & \\
$7-20$ & $236(9.9)$ & $697(9.7)$ & $0.85(0.70,1.04)$ & \\
\hline
\end{tabular}

Time between diagnosis and last prescription (years)

\begin{tabular}{|l|c|c|c|c|}
\hline Never & $1798(75.2)$ & $5397(75.3)$ & 1.00 & 0.300 \\
$>1$ & $445(18.6)$ & $1365(19.1)$ & $0.83(0.71,0.97)$ & \\
$2-14$ & $149(6.2)$ & $403(5.6)$ & $0.99(0.81,1.23)$ & \\
\hline
\end{tabular}

Total number of prescriptions

\begin{tabular}{|l|c|c|c|c|}
\hline Never & $1798(75.2)$ & $5397(75.3)$ & 1.00 & 0.017 \\
$1-7$ & $202(8.4)$ & $571(8.0)$ & $0.95(0.79,1.15)$ & \\
$8-28$ & $198(8.3)$ & $603(8.4)$ & $0.83(0.68,1.01)$ & \\
$29-147$ & $194(8.1)$ & $594(8.3)$ & $0.79(0.64,0.99)$ & \\
\hline
\end{tabular}

Average number of prescriptions per year ${ }^{c}$

\begin{tabular}{|c|c|c|c|c|}
\hline Never & $1798(75.2)$ & $5397(75.3)$ & 1.00 & 0.122 \\
\hline $0.4-4$ & $155(6.5)$ & $443(6.2)$ & $0.88(0.70,1.09)$ & \\
\hline $5-7$ & 207 (8.7) & $642(9.0)$ & $0.82(0.67,1.00)$ & \\
\hline $8-40$ & $232(9.7)$ & $683(9.5)$ & $0.90(0.75,1.07)$ & \\
\hline \multicolumn{5}{|c|}{ 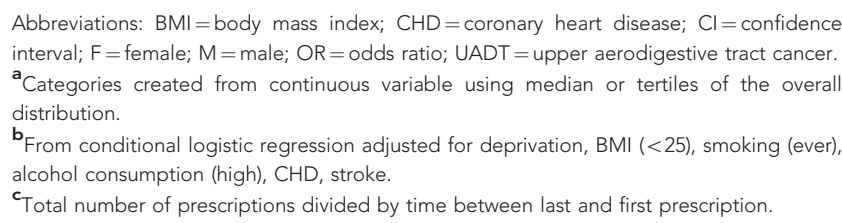 } \\
\hline
\end{tabular}

priority for further investigation using major studies and other data sources.

\section{ACKNOWLEDGEMENTS}

We thank the PCCIUR staff and Data Management Team for preparing the data for this study: James Bellarby, Katie Wilde, Fiona Chaloner. We are grateful to anonymous reviewers of the manuscript for helpful comments and suggestions. 


\section{AUTHOR CONTRIBUTIONS}

TVM had the original idea for this study, contributed to the study design, undertook all the statistical analyses and wrote the first draft of the paper. MCW and KL contributed to the development of the idea, design and interpretation and worked on further drafts of the paper.

\section{REFERENCES}

Austin PC (2011) An Introduction to propensity score methods for reducing the effects of confounding in observational studies. Multivariate Behav Res 46(3): 399-424.

Bosetti C, Talamini R, Franceschi S, Negri E, Garavello W, La Vecchia C (2003) Aspirin use and cancers of the upper aerodigestive tract. $\mathrm{Br} J$ Cancer 88: 672-674.

Carstairs V, Morris R (1989) Deprivation, mortality and resource allocation. Community Med 11(4): 364-372.

Chaturvedi AK, Anderson WF, Lortet-Tieulent J, Curado MP, Ferlay J, Franceschi S, Rosenberg PS, Bray F, Gillison ML (2013) Worldwide trends in incidence rates for oral cavity and oropharyngeal cancers. J Clin Oncol 31(36): 4550-4559.

Conway DI, McKinney PA, McMahon AD, Ahrens W, Schmeisser N, Benhamou S, Bouchardy C, Macfarlane GJ, Macfarlane TV, Lagiou P, Minaki P, Bencko V, Holcátová I, Merletti F, Richiardi L, Kjaerheim K, Agudo A, Castellsague X, Talamini R, Barzan L, Canova C, Simonato L, Lowry RJ, Znaor A, Healy CM, McCartan BE, Marron M, Hashibe M, Brennan P (2010) Socioeconomic factors associated with risk of upper aerodigestive tract cancer in Europe. Eur J Cancer 46(3): 588-598.

Dregan A, Moller H, Murray-Thomas T, Gulliford MC (2012) Validity of cancer diagnosis in a primary care database compared with linked cancer registrations in England. Population-based cohort study. Cancer Epidemiol 36: $425-429$.

Elder R, Kirkpatrick M, Ramsay W, Macleod M, Guthrie B, Sutton M, Watt G (2007) Measuring Quality in Primary Medical Services Using Data from SPICE. NHS National Services Scotland: Edinburgh, Scotland.

Ferlay J, Shin HR, Bray F, Forman D, Mathers C, Parkin DM (2010) GLOBOCAN 2008, Cancer Incidence and Mortality Worldwide: IARC CancerBase No. 10 [Internet]. International Agency for Research on Cancer: Lyon, France, Available from http://globocan.iarc.fr.

Friis S, Poulsen A, Pedersen L, Baron JA, Sørensen HT (2006) Use of nonsteroidal anti-inflammatory drugs and risk of oral cancer: a cohort study. Br J Cancer 95: 363-365.

Garavello W, Bertuccio P, Levi F, Lucchini F, Bosetti C, Malvezzi M, Negri E, La Vecchia C (2010) The oral cancer epidemic in central and eastern Europe. Int J Cancer 127: 160-171.

Gaudet MM, Olshan AF, Chuang SC, Berthiller J, Zhang ZF, Lissowska J, Zaridze D, Winn DM, Wei Q, Talamini R, Szeszenia-Dabrowska N, Sturgis EM, Schwartz SM, Rudnai P, Eluf-Neto J, Muscat J, Morgenstern H, Menezes A, Matos E, Bucur A, Levi F, Lazarus P, La Vecchia C, Koifman S Kelsey K, Herrero R, Hayes RB, Franceschi S, Wunsch-Filho V, Fernandez L, Fabianova E, Daudt AW, Dal Maso L, Curado MP, Chen C, Castellsague X, Benhamou S, Boffetta P, Brennan P, Hashibe M (2010) Body mass index and risk of head and neck cancer in a pooled analysis of case-control studies in the International Head and Neck Cancer Epidemiology (INHANCE) Consortium. Int J Epidemiol 39(4): 1091-1102.

Goodin S, Shiff SJ (2004) NSAIDs for the chemoprevention of oral cancer: promise or pessimism? Commentary re: J L Mulshine et al. Randomized double-blind, placebo-controlled, phase IIB trial of the cyclooxygenase inhibitor ketorolac as an oral rinse in oropharyngeal leukoplakia. Clin Cancer Res 10: 1561-1564.

Hawkey CJ, Cullen DJE, Pearson G, Holmes S, Doherty M, Wilson JV, Garrud P, Garner S, Maynard A, Logan RFA (2000) Ibuprofen vs other non-steroidal anti-inflammatory drugs: use in general practice and patient perception. Aliment Pharmacol Ther 14: 187-191.

Hernández-Díaz S, Rodríguez LA (2000) Association between nonsteroidal anti-inflammatory drugs and upper gastrointestinal tract bleeding/ perforation: an overview of epidemiologic studies published in the 1990s. Arch Intern Med 160(14): 2093-2099.

Hernández-Díaz S, García Rodríguez LA (2007) Nonsteroidal anti-inflammatory drugs and risk of lung cancer. Int J Cancer 120(7): 1565-1572.
IARC Monographs on the Evaluation of Carcinogenic Risks to Humans (2004) Volume 83 - Tobacco Smoke and Involuntary Smoking, Lyon, France.

IARC Monographs on the Evaluation of Carcinogenic Risks to Humans (2010) Volume 96 Alcohol Consumption and Ethyl Carbamate, Lyon, France.

Jayaprakash V, Rigual NR, Moysich KB, Loree TR, Sullivan Nasca MA, Menezes RJ, Reid ME (2006) Chemoprevention of head and neck cancer with aspirin: a case-control study. Arch Otolaryngol Head Neck Surg 132: 1231-1236.

Jemal A, Center MM, DeSantis C, Ward EM (2010) Global patterns of cancer incidence and mortality rates and trends. Cancer Epidemiol Biomarkers Prev 19(8): 1893-1907.

Jemal A (2012) Global burden of cancer: opportunities for prevention. Lancet 380(9856): 1797-1799.

Junor EJ, Kerr GR, Brewster DH (2010) Oropharyngeal cancer. Fastest increasing cancer in Scotland, especially in men. BMJ 340: c2512.

Lagiou P, Talamini R, Samoli E, Lagiou A, Ahrens W, Pohlabeln H, Benhamou S, Bouchardy C, Slamova A, Schejbalova M, Merletti F, Richiardi L, Kjaerheim K, Agudo A, Castellsague X, Macfarlane TV, Macfarlane GJ, Biggs AM, Barzan L, Canova C, Simonato L, Lowry RJ, Conway DI, McKinney PA, Znaor A, McCartan BE, Healy CM, Marron M, Hashibe M, Brennan P (2009) Diet and upper-aerodigestive tract cancer in Europe: the ARCAGE study. Int J Cancer 124: 2671-2676.

Marchenko Y (2011) Chained equations and more in multiple imputation in Stata 12 UK Stata Users Group Meeting. http://www.stata.com/meeting/ uk11/abstracts/UK11_marchenko.pdf.

Macfarlane TV, Macfarlane GJ, Thakker NS, Benhamou S, Bouchardy C, Ahrens W, Pohlabeln H, Lagiou P, Lagiou A, Castellsague X, Agudo A, Slamova A, Plzak J, Merletti F, Richiardi L, Talamini R, Barzan L, Kjaerheim K, Canova C, Simonato L, Conway DI, McKinney PA, Thomson P, Sloan P, Znaor A, Healy CM, McCartan BE, Marron M, Brennan P (2012) Role of medical history and medication use in the aetiology of upper aerodigestive tract cancers in Europe: The ARCAGE study. Ann Oncol 23(4): 1053-1060.

Mehanna H, Jones TM, Gregoire V, Ang KK (2010) Oropharyngeal carcinoma related to human papillomavirus. BMJ 340: c1439.

Mork J, Lie AK, Glattre E, Hallmans G, Jellum E, Koskela P, Møller B, Pukkala E, Schiller JT, Youngman L, Lehtinen M, Dillner J (2001) Human papillomavirus infection as a risk factor for squamous-cell carcinoma of the head and neck. N Engl J Med 344(15): 1125-1131.

Nelson NJ (2006) Years of research come to fruition with launch of oral cancer prevention trial. J Natl Cancer Inst 98: 88-89.

Rothwell PM, Fowkes FG, Belch JFF, Ogawa H, Warlow CP, Meade TW (2011) Effect of daily aspirin on long-term risk of death due to cancer: analysis of individual patient data from randomised trials. Lancet 377: 31-41.

Rothwell PM, Price JF, Fowkes FG, Zanchetti A, Roncaglioni MC, Tognoni G, Lee R, Belch JF, Wilson M, Mehta Z, Meade TW (2012) Short-term effects of daily aspirin on cancer incidence, mortality, and non-vascular death: analysis of the time course of risks and benefits in 51 randomised controlled trials. Lancet 379(9826): 1602-1612.

Schneeweiss S, Glynn RJ, Tsai EH, Avorn J, Solomon DH (2005) Adjusting for unmeasured confounders in pharmacoepidemiologic claims data using external information: the example of COX2 inhibitors and myocardial infarction. Epidemiology 16: 17-24.

Thun MJ, Henley SJ, Patrono C (2002) Nonsteroidal anti-inflammatory drugs as anticancer agents: mechanistic, pharmacologic, and clinical issues. J Natl Cancer Inst 94: 252-266.

Vinogradova Y, Coupland C, Hippisley-Cox J (2011) Exposure to cyclooxygenase-2 inhibitors and risk of cancer: nested case-control studies. Br J Cancer 105(3): 452-459.

Warnakulasuriya S (2009) Causes of oral cancer-an appraisal of controversies. Br Dent J 207: 471-475.

Wilson JC, Anderson LA, Murray LJ, Hughes CM (2011) Non-steroidal anti-inflammatory drug and aspirin use and the risk of head and neck cancer: a systematic review. Cancer Causes Control 22: 803-810.

Yood MU, Campbell UB, Rothman KJ, Jick SS, Lang J, Wells KE, Jick H, Johnson CC (2007) Using prescription claims data for drugs available over-the-counter (OTC). Pharmacoepidemiol Drug Saf 16(9): 961-968.

This work is published under the standard license to publish agreement. After 12 months the work will become freely available and the license terms will switch to a Creative Commons AttributionNonCommercial-Share Alike 3.0 Unported License. 


\begin{tabular}{|l|l|}
\hline APPENDIX 1 \\
\hline Aceclofenac & Lederfen \\
\hline Acemetacin & Lodine \\
\hline Arthrotec & Mefenamic acid \\
\hline Azapropazone & Meloxicam \\
\hline Brexidol & Mobic \\
\hline Brufen & Mobiflex \\
\hline Caprin & Motifene \\
\hline Clinoril & Motrin \\
\hline Co-codaprin & Nabumetone \\
\hline Codafen continus & Napratec \\
\hline Dexketoprofen & Naprosyn \\
\hline Diclofenac & Naproxen \\
\hline Diclomax & Nycopren \\
\hline Diflunisal & Oruvail \\
\hline Dolobid & Piroxicam \\
\hline Etodolac & Ponstan \\
\hline Feldene & Preservex \\
\hline Fenbid & Relifex \\
\hline Fenbufen & Rheumox \\
\hline Fenoprofen & Rhumalgan CR \\
\hline Flurbiprofen & Sulindac \\
\hline Froben & Surgam \\
\hline Froben-p42 & Synflex \\
\hline Ibuprofen & Tenoxicam \\
\hline Indomax SR & Tiaprofenic acid \\
\hline Indometacin & Volsaid retard \\
\hline Keral & Voltarol \\
\hline Ketoprofen & \\
\hline & \\
\hline
\end{tabular}

